\title{
Comparative in vitro antimicrobial potency, stability, colouration and dissolution time of generics versus innovator of meropenem in Europe
}

\author{
Isabelle K. Delattre ${ }^{\mathrm{a}, \mathrm{b}}$, Caroline Briquet ${ }^{\mathrm{c}}$, Pierre Wallemacq ${ }^{\mathrm{b}, \mathrm{d}}$, Paul M. Tulkens ${ }^{\mathrm{a}}$, \\ Françoise Van Bambeke ${ }^{\mathrm{a}, *}$ \\ a Pharmacologie cellulaire et moléculaire, Louvain Drug Research Institute, Université catholique de Louvain (UCLouvain), Brussels, Belgium \\ ${ }^{\mathrm{b}}$ Louvain Centre for Toxicology and Applied Pharmacology, Université catholique de Louvain (UCLouvain), Brussels, Belgium \\ ${ }^{\mathrm{c}}$ Pharmacie, Cliniques universitaires St-Luc, Université catholique de Louvain (UCLouvain), Brussels, Belgium \\ ${ }^{\mathrm{d}}$ Département des laboratoires cliniques, Cliniques universitaires Saint-Luc, Université catholique de Louvain (UCLouvain), Brussels, Belgium
}

\section{A R T I C L E I N F O}

\section{Article history:}

Received 26 August 2019

Accepted 11 October 2019

Editor: Prof. H. Derendorf

\section{Keywords:}

Generics

Meropenem

Degradation

Colouration

Stability

Dissolution

\begin{abstract}
A B S T R A C T
Meropenem generics are often imposed on prescribers, however scarce information is available on key properties such as antimicrobial potency, stability and colouration in solution, and dissolution time. This study aimed to generate comparative information for products available in Europe. The originator (ASTRA) and four generics (HOSPIRA, SANDOZ, FRESENIUS and AUROVIT) were compared for: (i) MICs against Pseudomonas aeruginosa clinical isolates (range, 0.125-191 mg/L); (ii) colouration (visual and photometry) and stability of concentrated solutions for prolonged or continuous infusion and maintained at $25-37{ }^{\circ} \mathrm{C}$ for up to $8 \mathrm{~h}$ (acceptable limit, $\geq 90 \%$ of original concentration); and (iii) dissolution time of concentrated solutions ( $50 \mathrm{mg} / \mathrm{mL}$ [for bolus administration]: turbidimetry and nursing personnel assessment). No significant difference was observed for MICs (except 2/80 isolates). For concentrated solutions storage: (i) SANDOZ produced about two times more yellow-coloured degradation products than the other preparations; (ii) meropenem loss was time-, concentration- and temperature-dependent; (iii) FRESENIUS was the least stable (limit for $1 \mathrm{~g} / 48 \mathrm{~mL}, \sim 8 \mathrm{~h}$ at $25{ }^{\circ} \mathrm{C}$ and $4.5 \mathrm{~h}$ at $37{ }^{\circ} \mathrm{C}$ ); (iv) at $2 \mathrm{~g} / 48 \mathrm{~mL}$, the storage time limit was $5-6 \mathrm{~h}$ at $25{ }^{\circ} \mathrm{C}$ and $\sim 3 \mathrm{~h}$ at $37{ }^{\circ} \mathrm{C}$ for all preparations. Complete dissolution (turbidimetry) required $240 \mathrm{~s}$ for generics (120 s for ASTRA), and nurses reported longer but highly variable times for generics. Substantial differences between innovator and generics have been identified that could impact on their clinical use and/or make multicentric studies difficult to interpret, requiring suitability studies in the environments of their intended use.
\end{abstract}

(c) 2019 Elsevier B.V. and International Society of Chemotherapy. All rights reserved.

\section{Introduction}

Meropenem is frequently used in intensive care units (ICUs) for treating severe infections caused by organisms resistant to other antibiotics, such as Pseudomonas aeruginosa. As a $\beta$-lactam, its activity is dependent upon the time during which plasma concentrations remain above the minimum inhibitory concentration (MIC) of the causative pathogen, prompting its use by extendedinfusion administration [1]. However, this raises questions of stability [2] that limit its officially approved infusion time to 15$30 \mathrm{~min}$ and its storage at $25{ }^{\circ} \mathrm{C}$ to $3 \mathrm{~h}$ [3]. Yet, using the original product (Meronem ${ }^{\circledR}$; AstraZeneca), we and others have suggested

\footnotetext{
* Corresponding author at: Pharmacologie cellulaire et moléculaire, Louvain Drug Research Institute, avenue E. Mounier 73 Bte B1.73.05, B-1200 Brussels, Belgium. Tel.: +32 27647378 .

E-mail addresses: tulkens@facm.ucl.ac.be (P.M. Tulkens), francoise.vanbambeke@uclouvain.be (F. Van Bambeke).
}

that storage up to $8 \mathrm{~h}$ would be acceptable provided the storage temperature remains $\leq 25{ }^{\circ} \mathrm{C}[2,4-7]$. However, the situation has increased in complexity by the introduction of generics (often imposed on the prescriber and not necessarily the same in different hospitals) for which detailed stability studies are often lacking. Moreover, there is published evidence for variations in properties such as solubility rate [8] that may become critical when using concentrated solutions. The present work was undertaken in the context of a multicentric study to test for potential differences in antimicrobial activity, stability and dissolution times of generics used in three hospitals in Europe (Belgium, France and Spain) in comparison with the originator.

\section{Methods}

Meropenem [powder for intravenous (i.v.) injection] was obtained through the hospital pharmacies as supplied by AstraZeneca (Belgium; originator; hereafter referred to ASTRA), HOSPIRA 
(Belgium), SANDOZ (Belgium), FRESENIUS-KABI (Belgium and France; hereafter referred to FRESENIUS) or AUROVIT (Spain). All were used before their expiration date. Other products were from Sigma-Aldrich (St Louis, MO, USA), Merck AG (Darmstadt, Germany) or procured from the hospital pharmacies.

Non-duplicate isolates of $P$. aeruginosa were from patients with a diagnosis of nosocomial pneumonia [9]. MICs were measured by broth microdilution according to Clinical and Laboratory Standards Institute (CLSI) recommendations in cation-adjusted Mueller-Hinton broth (BD Diagnostics, Franklin Lakes, NJ, USA) but using arithmetic progression (see Results) and were categorised for susceptibility according to the interpretive criteria of the European Committee on Antimicrobial Susceptibility Testing (EUCAST).

Meropenem solutions were prepared in $0.9 \% \mathrm{NaCl}$ (pharmaceutical grade) to mimic their intended use by prolonged or continuous infusion and were kept at defined temperatures for up to $8 \mathrm{~h}$ in the dark (to avoid potential photochemical degradation) [10]. Colouration was assessed visually and photometrically using a SpectraMax ${ }^{\circledR}$ M Series Multi-Mode Microplate Reader (Molecular Devices, LLC, San Jose, CA, USA). Stability of meropenem was tested using liquid chromatography/tandem mass spectrometry (LC-MS/MS) (see Supplementary Methods for details) and the rate of its disappearance was determined by linear regression

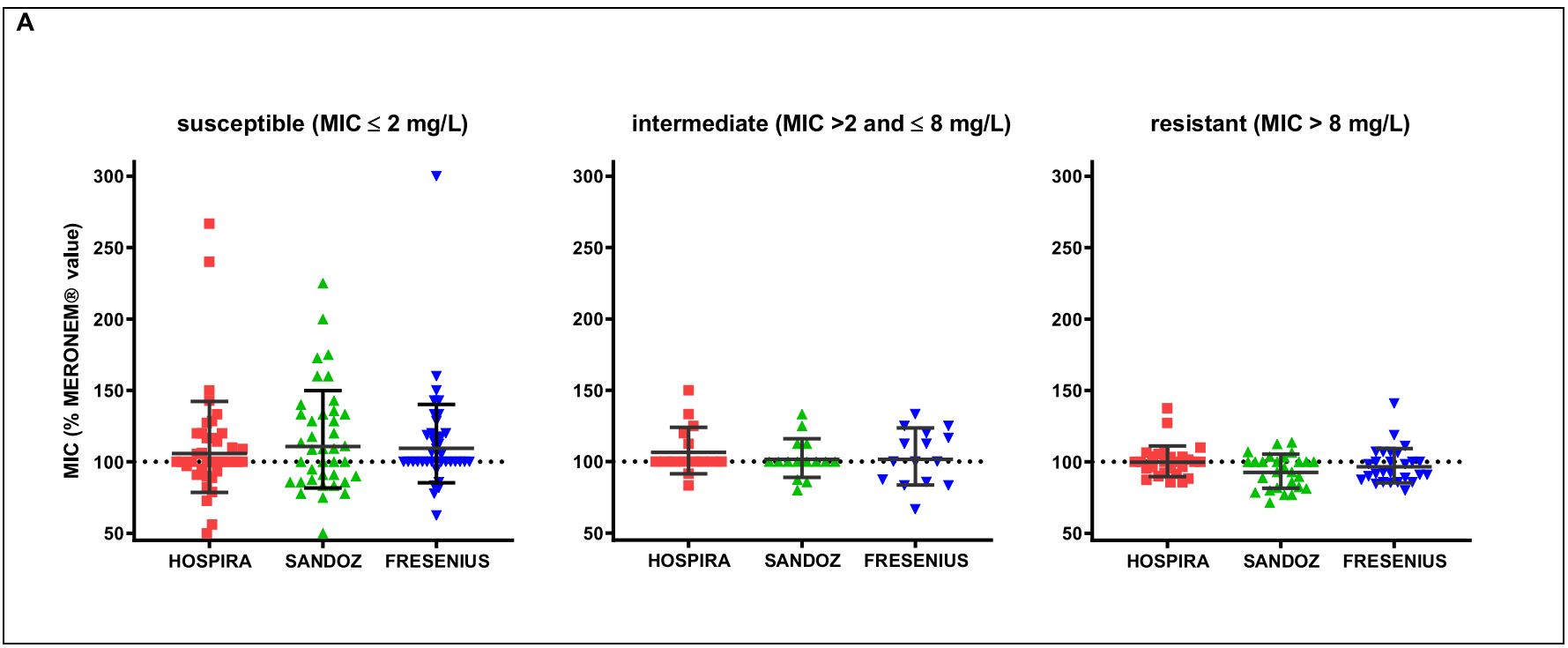

B
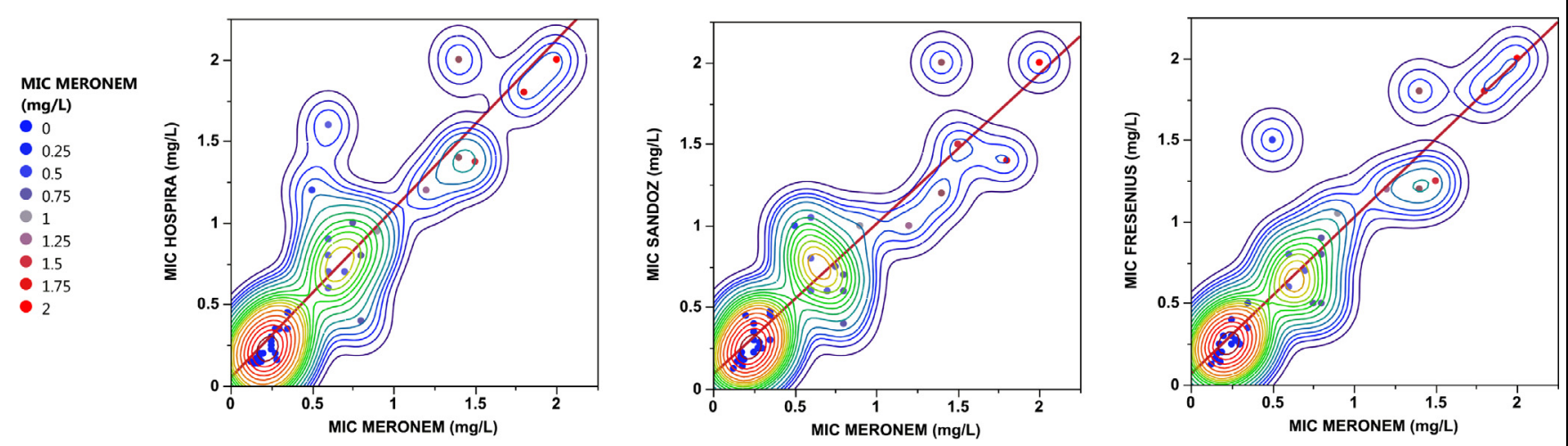

一 Linear Fit

1.2.3.4.5.6.7.8.9 Quantile Density Contours

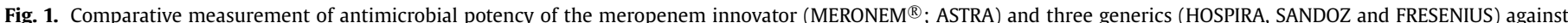

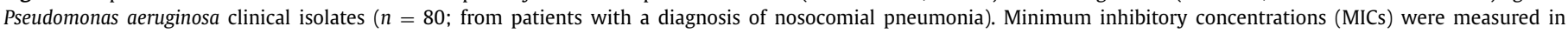

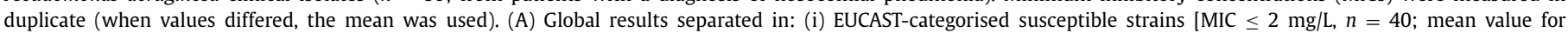

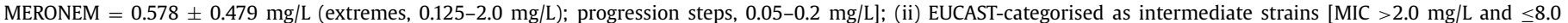

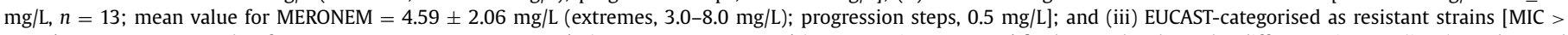

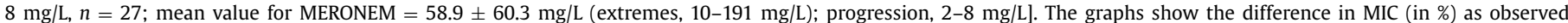

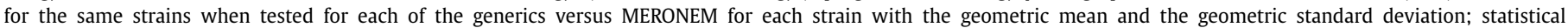

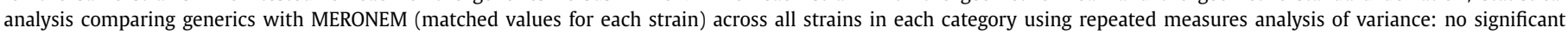

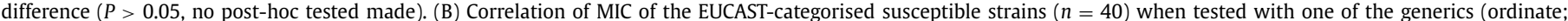

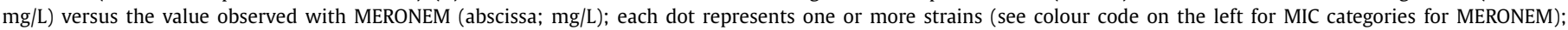

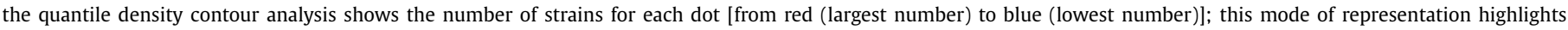

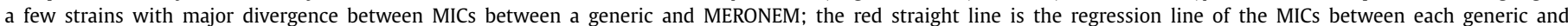

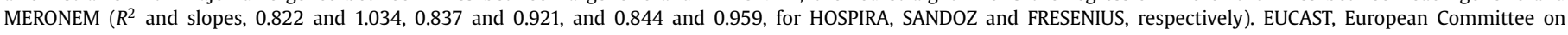
Antimicrobial Susceptibility Testing. 


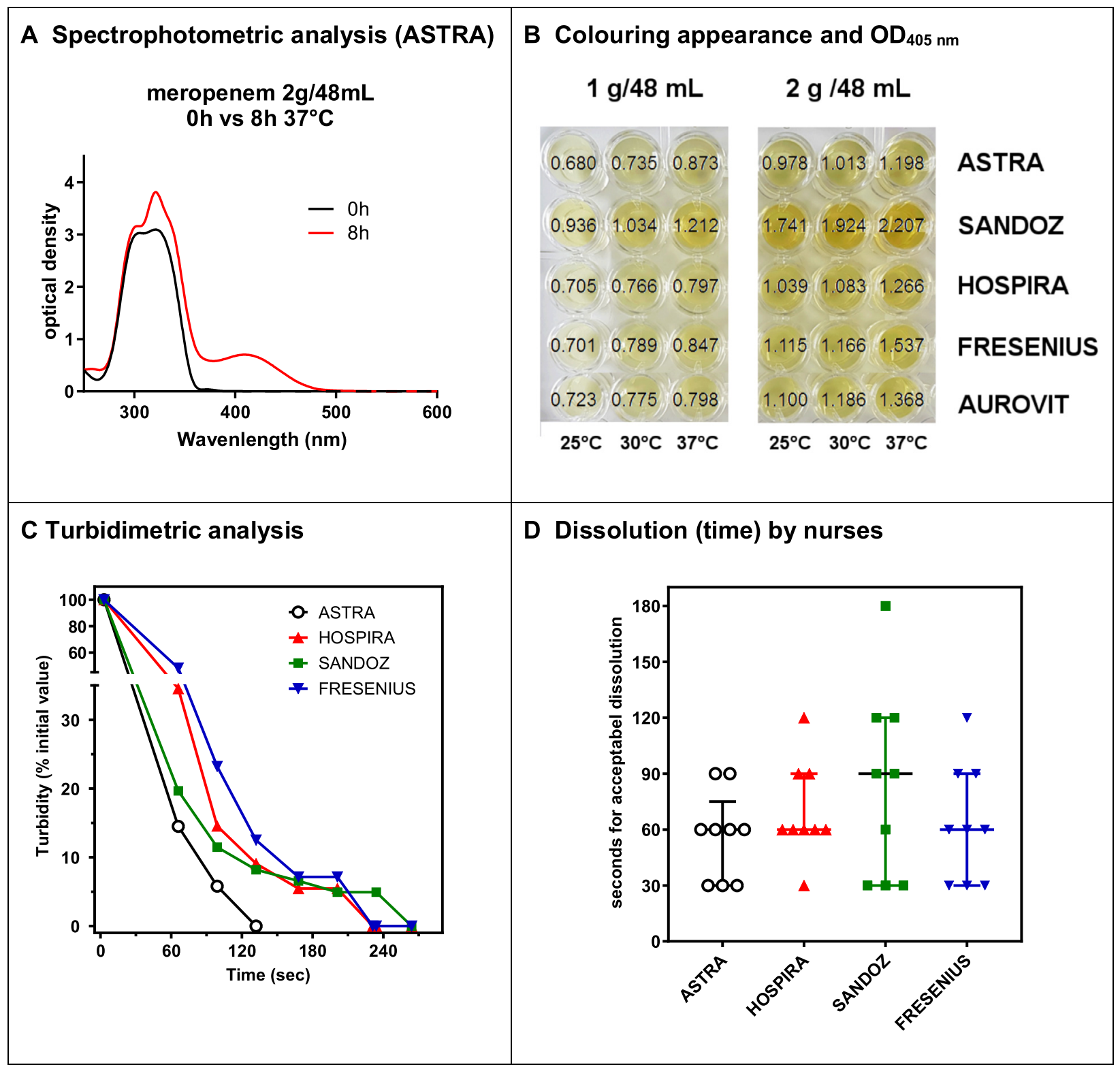

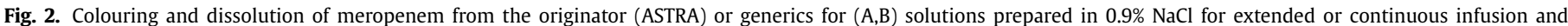

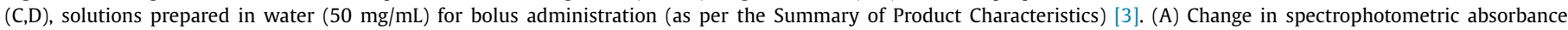

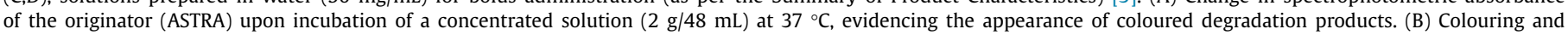

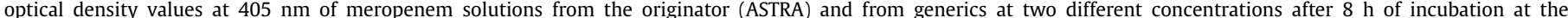

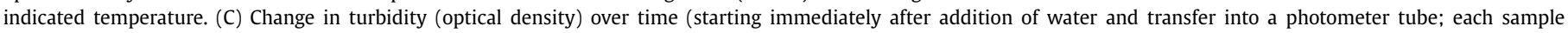

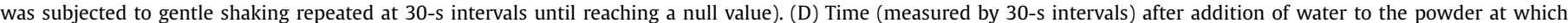

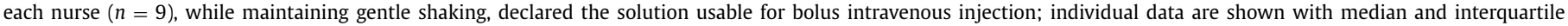
range; statistical analysis (non-parametric analysis, Kruskal-Wallis test), non-significant.

of data (limited to situations with $<20 \%$ loss from the original concentration) with calculation of the $95 \%$ confidence interval. As proposed previously [6,11-13], meropenem was considered as staying stable as long as its content remained $\geq 90 \%$ of the original value.

Dissolution studies mimicking the approved bolus administration of meropenem consisted of dissolving $0.5 \mathrm{~g}$ in $10 \mathrm{~mL}$ of water (as per the instructions for use in the corresponding Summary of Product Characteristics [3]). In the laboratory, turbidity was measured over time using a BioSan Densitometer (BioSan Medical-Biological Research \& Technologies, Riga, Latvia) with gentle shaking every $30 \mathrm{~s}$. In wards, nurses $(n=9$, blinded to the type of drug used) had to shake the vial and declare when, in their judgement, the solution was clear and usable for i.v. injection (time noted by an observer and entered in the closest corresponding 30-s interval).

Decay and statistical analyses were performed with GraphPad InStat v.3.10 and GraphPad Prism v.8.2.0 from GraphPad Software Inc. (San Diego, CA, USA; http://www.graphpad.com) and MIC correlation analyses with JMP Pro v.14.3.0 (SAS Institute, Cary, NC, USA; http://www.jmp.com).

\section{Results}

\subsection{In vitro activity against Pseudomonas aeruginosa}

MICs taken globally (80 isolates; MIC range, 0.125-191 mg/L) or subdivided by susceptibility categories (Fig. 1A; 40 susceptible, 
Table 1

Incubation time at which the meropenem concentration had fallen to $90 \%$ of its original value for the originator (ASTRA) and four generics.

\begin{tabular}{|c|c|c|c|c|c|c|}
\hline \multirow[t]{3}{*}{ Source } & \multicolumn{6}{|l|}{ Time $(\mathrm{h})$} \\
\hline & \multicolumn{3}{|c|}{ Meropenem $1 \mathrm{~g} / 48 \mathrm{~mL}$ (in $\mathrm{NaCl} 0.9 \%$ ) } & \multicolumn{3}{|c|}{ Meropenem $2 \mathrm{~g} / 48 \mathrm{~mL}$ (in $\mathrm{NaCl} 0.9 \%$ ) } \\
\hline & $25^{\circ} \mathrm{C}$ & $30^{\circ} \mathrm{C}$ & $37^{\circ} \mathrm{C}$ & $25^{\circ} \mathrm{C}$ & $30^{\circ} \mathrm{C}$ & $37^{\circ} \mathrm{C}$ \\
\hline ASTRA & $21.2 \pm 2.2 \mathrm{a}$ & $14.9 \pm 2.6 \mathrm{a}, \mathrm{d}$ & $9.7 \pm 1.0 \mathrm{a}$ & $4.9 \pm 0.4 \mathrm{a}$ & $4.2 \pm 0.3 \mathrm{a}$ & $3.1 \pm 0.2 \mathrm{a}$ \\
\hline HOSPIRA & $41.1 \pm 14.0$ b,e & $12.7 \pm 2.3 \mathrm{a}, \mathrm{b}$ & $7.7 \pm 1.3 \mathrm{~b}$ & $5.6 \pm 0.2 b$ & $3.7 \pm 0.1 \mathrm{~b}$ & $3.0 \pm 0.2 \mathrm{a}, \mathrm{b}$ \\
\hline SANDOZ & $18.7 \pm 3.4 \mathrm{a}$ & $12.5 \pm 1.7 \mathrm{~b}$ & $4.5 \pm 0.2 c$ & $5.1 \pm 0.3 a$ & $3.4 \pm 0.2 \mathrm{c}$ & $2.9 \pm 0.1 \mathrm{a}, \mathrm{c}$ \\
\hline FRESENIUS & $8.1 \pm 0.8 \mathrm{c}, \mathrm{f}$ & $5.5 \pm 0.3 c$ & $4.5 \pm 0.3 \mathrm{c}, \mathrm{d}$ & $4.9 \pm 0.4 \mathrm{a}$ & $3.8 \pm 0.2 \mathrm{~b}$ & $3.0 \pm 0.2 \mathrm{a}, \mathrm{c}$ \\
\hline AUROVIT & $31.3 \pm 5.5 \mathrm{~d}$ & $16.1 \pm 1.6 \mathrm{~d}$ & $10.0 \pm 0.9 \mathrm{a}$ & $6.0 \pm 0.3 b$ & $4.2 \pm 0.2 \mathrm{a}$ & $3.0 \pm 0.1 \mathrm{a}, \mathrm{c}$ \\
\hline
\end{tabular}

The change in meropenem concentration was measured (in triplicate) from samples taken at $0 \mathrm{~h}, 0.5 \mathrm{~h}$, and then hourly up to $8 \mathrm{~h}$. The rate of meropenem disappearance was calculated by linear regression [limited to the zone of linearity (max. $20 \%$ degradation)] with $95 \%$ confidence interval and was used to determine the time ( \pm standard deviation) at which the meropenem concentration had or would have fallen to $90 \%$ of its value at $0 \mathrm{~h}$. Statistical analyses:

1. Effect of concentration [comparing at the same temperature $\left(25,30\right.$ or $\left.37{ }^{\circ} \mathrm{C}\right)$ meropenem solutions from the same source but at $1 \mathrm{~g} / 48 \mathrm{~mL}$ vs. $2 \mathrm{~g} / 48 \mathrm{~mL}$ ]: extremely significant for each source $(P<0.0001$, unpaired $t$-test two-tailed); 2. Effect of temperature [comparing at the same concentration $(1 \mathrm{~g} / 48 \mathrm{~mL}$ or $2 \mathrm{~g} / 48 \mathrm{~mL})$ meropenem solutions from the same source but at 25,30 or $\left.37^{\circ} \mathrm{C}\right]$ : extremely significant $(P<0.0001)$ by repeated analysis of variance (ANOVA) when considering all data, with $P<0.001$ for Tukey-Kramer multiple comparisons post-hoc test, except for FRESENIUS $1 \mathrm{~g} 30^{\circ} \mathrm{C}$ vs. FRESENIUS $1 \mathrm{~g} 37^{\circ} \mathrm{C}(P<0.01)$, AUROVIT $1 \mathrm{~g} 30^{\circ} \mathrm{C}$ vs. AUROVIT $1 \mathrm{~g} 37{ }^{\circ} \mathrm{C}(P<0.01)$ and HOSPIRA $1 \mathrm{~g} 30{ }^{\circ} \mathrm{C}$ vs. HOSPIRA $1 \mathrm{~g} 37^{\circ} \mathrm{C}(P>0.05$, not significant $)$.

3. Effect of source [comparing at one temperature $\left(25,30\right.$ or $\left.37{ }^{\circ} \mathrm{C}\right)$ and at one concentration $(1 \mathrm{~g} / 48 \mathrm{~mL}$ or $2 \mathrm{~g} / 48 \mathrm{~mL})$ meropenem solutions prepared from different sources (ASTRA, HOSPIRA, SANDOZ, FRESENIUS or AUROVIT)]: figures with different letters are significantly different from each other (ANOVA with Tukey-Kramer multiple comparisons post-hoc test; $P<0.05$ ).

13 intermediate and 27 resistant) were not significantly different between the originator (ASTRA) and the three generics tested. However, among susceptible isolates, (i) two showed an MIC $\geq 2$ times higher for HOSPIRA or SANDOZ compared with ASTRA, and one for FRESENIUS (one common to all three generics), which, however, did not affect their categorisation; (ii) the correlation slopes (linear regression) between ASTRA and SANDOZ or FRESENIUS were only 0.921 or 0.959 , respectively (Fig. 1B), suggesting that these generics were slightly less potent (but, again, not to the extent of changing the categorisation of the isolates).

\subsection{Colouration and stability}

Meropenem preparations ( $1 \mathrm{~g}$ or $2 \mathrm{~g}$ in $48 \mathrm{mg} / \mathrm{L}$ ) as used in ICUs (via motor-operated syringes) quickly get coloured upon storage. Fig. 2A shows the change in absorption spectrum for the originator (ASTRA) after storage of a $2 \mathrm{~g} / 48 \mathrm{~mL}$ solution at $37{ }^{\circ} \mathrm{C}$ for $8 \mathrm{~h}$, evidencing two additional peaks at $320 \mathrm{~nm}$ and $405 \mathrm{~nm}$. Fig. 2B shows the colour appearance for all preparations at all conditions tested, with the numeric values of the corresponding spectrophotometric absorptions at $405 \mathrm{~nm}$. SANDOZ clearly yielded more coloured product(s) than others in all conditions (also observed for solutions prepared in water, ruling out a possible role of the matrix).

The same preparations were used to measure the decay of meropenem concentration (see typical results in two conditions corresponding to the extremes of concentration and temperature tested with the originator in Supplementary Fig. S1). The loss of meropenem over time was both concentration- and temperaturedependent for all preparations. Table 1 shows the time needed to reduce the meropenem concentration to $90 \%$ of its original value in each condition tested for each preparation. At $1 \mathrm{~g} / 48 \mathrm{~mL}$, FRESENIUS was the least stable, with the $90 \%$ limit reached after only $\sim 8 \mathrm{~h}$ at $25^{\circ} \mathrm{C}$ and $4.5 \mathrm{~h}$ at $37{ }^{\circ} \mathrm{C}$. At $2 \mathrm{~g} / 48 \mathrm{~mL}$, this $90 \%$ limit was reached after $\sim 5-6 \mathrm{~h}$ at $25{ }^{\circ} \mathrm{C}$ and after only $\sim 3 \mathrm{~h}$ at $37{ }^{\circ} \mathrm{C}$ for all preparations.

\subsection{Dissolution time}

Fig. 2C shows that the turbidity of meropenem solutions prepared from the originator (ASTRA) decreased rapidly, reaching a null value within $\sim 130$ s. Solutions from HOSPIRA and FRESENIUS showed an initial delay in dissolution, and all three generics showed a plateau in turbidity (incomplete dissolution) for up to $200 \mathrm{~s}$ (HOSPIRA and FRESENIUS) or $230 \mathrm{~s}$ (SANDOZ). Fig. 2D shows the shaking time after which individual nurses declared the solution suitable for i.v. injection. Whilst there was large variability between individuals, times in excess of $90 \mathrm{~s}$ were more frequent for the generics (especially SANDOZ) than for the originator (ASTRA), but were only once above $120 \mathrm{~s}$.

\section{Discussion}

Generics represent a large share of total antibiotic consumption and are often the only available forms to clinicians. Current European approval regulations $[14,15]$ imply that generics should have the same qualitative and quantitative composition in active substances and the same pharmaceutical form as the reference medicinal product, but bioavailability studies are not required for drugs intended for parenteral administration. This raises concerns, as key properties that may affect the overall therapeutic effectiveness and safety of an antibiotic, such as antimicrobial activity, stability, appearance of degradation products, and rapid and complete dissolution, are usually not tested. The present study examines these aspects for meropenem within the context of its proposed use for treatment of severe infections caused by $P$. aeruginosa in ICUs.

This study of the antimicrobial activity yielded reassuring results since all tested compounds showed essentially similar MICs throughout the whole panel of clinical isolates used, if very rare deviations limited to susceptible strains (and not affecting their categorisation) are disregarded, the nature and impact of which nevertheless remain to be determined. The slightly lower potency of SANDOZ and FRESENIUS compared with ASTRA could be considered as very minor. Thus, the generics tested showed reasonable equivalence with the originator regarding their in vitro potency, suggesting that they could be used interchangeably as far as their antimicrobial potency is concerned.

The situation and our conclusions are, however, less optimistic regarding the other properties tested. Indeed, we provide evidence for substantial differences with respect to stability, degradation, and ease and rate of dissolution. We first confirm here that 
meropenem is unstable in solution, with the present study documenting that only low concentration solutions ( $1 \mathrm{~g}$ in $48 \mathrm{~mL}$ ) can be stored for up to $8 \mathrm{~h}$ if maintained at $\leq 25{ }^{\circ} \mathrm{C}$ as previously reported [2,5-7], ruling out the indiscriminate use of meropenem by continuous infusion if using concentrated solutions under conditions where renewal of storage containers and temperature are not under strict control. Particularly worrying is that one generic (FRESENIUS) was clearly less stable, implying that its use in uncontrolled conditions could lead to insufficient therapeutic effects (faster degradation of a generic of imipenem compared with the originator has been shown to result in non-therapeutic equivalence if using discriminating animal models [16]). We also document here that more coloured product(s) are released from SANDOZ than from the originator (even though storage was in light-protected containers), opening the possibility of adverse effects, as suggested from cytotoxicity studies of meropenem degradation products [17]. Lastly, we also demonstrate that generics take a longer time to achieve complete dissolution (possibly due to the presence of coarser particles [8]), a potential problem for safe bolus administration, which was not clearly recognised by the nursing team (hence the shorter median times reported) but could create definite issues when drug solutions are prepared under time pressure as is often the case in many wards.

This study has obvious limitations. First, meropenem preparations from only five suppliers and obtained once were tested, meaning that the conclusions cannot be applied blindly to other batches, other suppliers, and certainly not other antibiotics. Second, we did not attempt to study the reasons (chemical, physical, others, etc.) for the differences noted in the context of this study since these could be fairly complex, specific to each product and situation, and would require considerable time and effort, including the use of sophisticated analytical techniques (see, for instance, our previous work characterising the degradation products originating from doripenem and meropenem [4]). Third, we did not test for therapeutic equivalence in animals [18] or patients [19] owing to insufficient support for conducting such studies at a meaningful scale. But because what we saw applies to generics that were approved for clinical use by the official authorities of the countries where they were made available to us, we suggest that there is a definite need for determining the actual suitability of each generic compared with the innovator in the specific environment(s) where it will be used.

\section{Acknowledgments}

The authors thank the hospital pharmacies of the Cliniques universitaires St-Luc (Brussels, Belgium), Hôpital Universitaire Pitié Salpêtrière (Paris, France) and Hospital Universitario Ramón y Cajal (Madrid, Spain) for providing us with the samples of drug used in this study. The authors also thank Pierre Muller for skilful technical help, and the nursing team of the Cliniques universitaires St-Luc for participating in the dissolution studies reported here.

Funding: This work was undertaken within the MON4STRAT programme [European Union's Seventh Framework Programme for research, technological development and demonstration; grant agreement no. 602906] and received a grant-in-aid from AstraZeneca NV/SA (Brussels, Belgium).

Competing interests: PMT has received speaker's honoraria from Bayer for presentations regarding generics of antibiotics. All other authors declare no competing interests.
Ethical approval: Not required.

\section{Supplementary materials}

Supplementary material associated with this article can be found, in the online version, at doi:10.1016/j.ijantimicag.2019.10. 006.

\section{References}

[1] Yu Z, Pang X, Wu X, Shan C, Jiang S. Clinical outcomes of prolonged infusion (extended infusion or continuous infusion) versus intermittent bolus of meropenem in severe infection: a meta-analysis. PLoS One 2018:13:e0201667.

[2] Viaene E, Chanteux H, Servais H, Mingeot-Leclercq MP, Tulkens PM. Comparative stability studies of antipseudomonal $\beta$-lactams for potential administration through portable elastomeric pumps (home therapy for cystic fibrosis patients) and motor-operated syringes (intensive care units). Antimicrob Agents Chemother 2002;46:2327-32.

[3] AstraZeneca. MERONEM ${ }^{\circledR}$ summary of product characteristics. http://bijsluiters. fagg-afmps.be/?localeValue=fr [accessed 15 August 2019].

[4] Berthoin K, Le Duff CS, Marchand-Brynaert J, Carryn S, Tulkens PM. Stability of meropenem and doripenem solutions for administration by continuous infusion. J Antimicrob Chemother 2010;65:1073-5.

[5] Keel RA, Sutherland CA, Crandon JL, Nicolau DP. Stability of doripenem, imipenem and meropenem at elevated room temperatures. Int J Antimicrob Agents 2011;37:184-5.

[6] Carlier M, Stove V, Verstraete AG, De Waele JJ. Stability of generic brands of meropenem reconstituted in isotonic saline. Minerva Anestesiol 2015;81:283-7.

[7] Tomasello C, Leggieri A, Cavalli R, Di Perri G, D'Avolio A. In vitro stability evaluation of different pharmaceutical products containing meropenem. Hosp Pharm 2015;50:296-303.

[8] Fujimura S, Watanabe A. Generic antibiotics in Japan. J Infect Chemother 2012;18:421-7.

[9] Riou M, Carbonnelle S, Avrain L, Mesaros N, Pirnay JP, Bilocq F, et al. In vivo development of antimicrobial resistance in Pseudomonas aeruginosa strains isolated from the lower respiratory tract of intensive care unit patients with nosocomial pneumonia and receiving antipseudomonal therapy. Int J Antimicrob Agents 2010;36:513-22.

[10] Reina AC, Martinez-Piernas AB, Bertakis Y, Brebou C, Xekoukoulotakis NP, Aguera $A$, et al. Photochemical degradation of the carbapenem antibiotics imipenem and meropenem in aqueous solutions under solar radiation. Water Res 2018;128:61-70.

[11] Mendez ASL, Dalomo J, Steppe M, Schapoval EES. Stability and degradation kinetics of meropenem in powder for injection and reconstituted sample. J Pharm Biomed Anal 2006;41:1363-6.

[12] Franceschi L, Cojutti P, Baraldo M, Pea F. Stability of generic meropenem solutions for administration by continuous infusion at normal and elevated temperatures. Ther Drug Monit 2014;36:674-6.

[13] Fawaz S, Barton S, Whitney L, Swinden J, Nabhani-Gebara S. Stability of meropenem after reconstitution for administration by prolonged infusion. Hosp Pharm 2019;54:190-6.

[14] EUR-Lex. EU rules on the authorisation, import and production of medicines for humans. https://eur-lex.europa.eu/legal-content/EN/TXT/?uri=LEGISSUM: 121230. Last updated 06-08-2015 [accessed 6 August 2019].

[15] European Medicines Agency (EMA). Human regulatory: generic and hybrid medicines. https://www.ema.europa.eu/en/human-regulatory/marketingauthorisation/generic-hybrid-medicines. Last updated 2019 [accessed 6 August 2019].

[16] Agudelo M, Rodriguez CA, Zuluaga AF, Vesga O. Nontherapeutic equivalence of a generic product of imipenem-cilastatin is caused more by chemical instability of the active pharmaceutical ingredient (imipenem) than by its substandard amount of cilastatin. PLoS One 2019;14:e0211096.

[17] Mendez A, Chagastelles P, Palma E, Nardi N, Schapoval E. Thermal and alkaline stability of meropenem: degradation products and cytotoxicity. Int J Pharm 2008;350:95-102

[18] Agudelo M, Rodriguez CA, Pelaez CA, Vesga O. Even apparently insignificant chemical deviations among bioequivalent generic antibiotics can lead to therapeutic nonequivalence: the case of meropenem. Antimicrob Agents Chemother 2014;58:1005-18.

[19] Ordóñez K, Feinstein MM, Reyes S, Hernández-Gómez C, Pallares C, Villegas MV. Clinical and economic impact of generic versus brand name meropenem use in an intensive care unit in Colombia. Braz J Infect Dis 2019;23:237-45. 


\section{Supplementary methods}

\section{Assay conditions of meropenem [liquid chromatography/tandem mass spectrometry (LC-MS/MS)]}

A Quattro Micro Tandem Mass Spectrometer (Micromass UK Ltd., Manchester, UK) fitted with a Z-spray ion source was used for the assay. The instrument was operated in positive electrospray ionisation mode and was directly coupled to a Waters 2795 Alliance High Throughput HPLC System (Waters, Milford, MA, USA). Chromatographic separation was achieved using a Kinetex C18 column $(100 \AA, 50 \times 3.0 \mathrm{~mm}, 2.6 \mu \mathrm{m}$ particle size; Phenomenex, Torrance, CA, USA) maintained at $30{ }^{\circ} \mathrm{C}$, with a mobile phase flow rate of $0.15 \mathrm{~mL} / \mathrm{min}[0.1 \%$ formic acid in water and $0.1 \%$ formic acid in methanol; isocratic elution (30/70\%, v/v)]. The multiple reaction monitoring transitions used for quantification were $\mathrm{m} / \mathrm{z} 384>141.32$ for meropenem and m/z 390.3>147.39 for its deuterated internal standard (IS) $\left(\left[{ }^{2} \mathrm{H}_{6}\right]-\right.$ meropenem; Alsachim, Illkirch, France), respectively. The cone voltage was set to 15 $\mathrm{V}$ and the collision energy to $15 \mathrm{eV}$ both for the antibiotic and its IS.

Sample preparation consisted of mixing $30 \mu \mathrm{L}$ of meropenem solution $(1 \mathrm{~g}$ or $2 \mathrm{~g}$ dissolved in $48 \mathrm{~mL} \mathrm{NaCl} \mathrm{0.9 \% ,} \mathrm{and} \mathrm{further} \mathrm{appropriately} \mathrm{diluted} \mathrm{to} \mathrm{obtain} \mathrm{a} \mathrm{final}$ dilution ratio of $1: 300$ ) with $30 \mu \mathrm{L}$ of the IS solution (10 mg/L in methanol) and $40 \mu \mathrm{L}$ of methanol in an Eppendorf tube. The injection volume and total run time were 10 $\mu \mathrm{L}$ and $5 \mathrm{~min}$, respectively. The autosampler temperature was set at $8^{\circ} \mathrm{C}$. Samples were prepared and assayed in triplicate. 
The method was fully validated over a 3-day period with five calibration curves per day (15 samples per concentration level, i.e. 0, 0.5, 1, 5, 10, 20, 50, 75, 100, 150 and $200 \mathrm{mg} / \mathrm{L}$ ) according to the published acceptance criteria [1-3] and displayed a between-run imprecision ranging from $0.8-4.7 \%$ with a limit of detection and limit of quantitation fixed at $0.1 \mathrm{mg} / \mathrm{L}$ and $0.5 \mathrm{mg} / \mathrm{L}$, respectively.

\section{References}

[1] International Council for Harmonisation (ICH). ICH harmonised tripartite guideline. Q2(R1) Validation of analytical procedures: text and methodology. November 2005. https://www.ich.org/page/quality-guidelines [accessed 25 November 2019].

[2] European Medicines Agency (EMA). Guideline on bioanalytical method validation. July 2011. https://www.ema.europa.eu/en/documents/scientificguideline/guideline-bioanalytical-method-validation_en.pdf [accessed 26 November 2019].

[3] US Food and Drug Administration (FDA). Guidance for industry: bioanalytical method validation. September 2013. http://academy.gmpcompliance.org/guidemgr/files/UCM368107.PDF [accessed 26 November 2019]. 


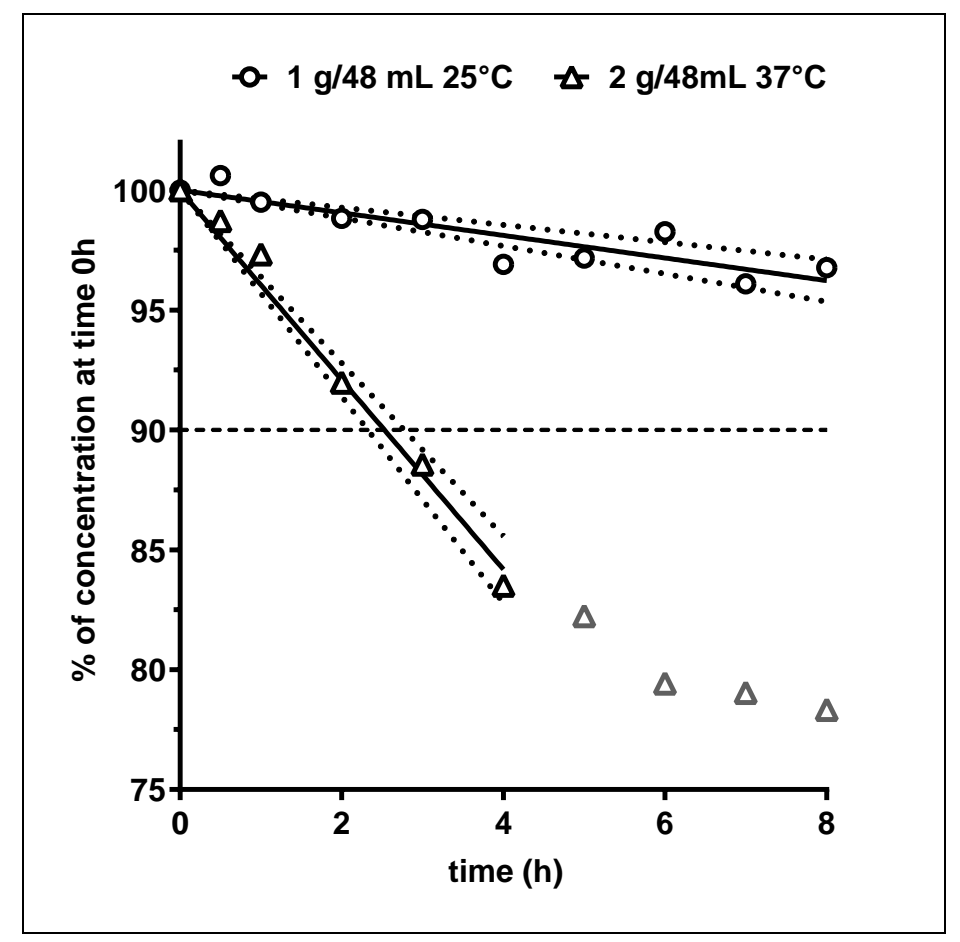

Supplementary Fig. S1. Typical changes in meropenem concentration following incubation of solutions prepared in $0.9 \% \mathrm{NaCl}$ [in this example, from the innovator (AstraZeneca)] at a low concentration and room temperature $\left(1 \mathrm{~g} / 48 \mathrm{~mL}, 25{ }^{\circ} \mathrm{C}\right.$; open circles) or a high concentration and body temperature $\left(2 \mathrm{~g} / 48 \mathrm{~mL}, 37^{\circ} \mathrm{C}\right.$; open triangles). Each point is the mean of triplicate determinations. Degradation rates (with $95 \% \mathrm{Cl}$ ) were calculated using the slope of linear regression of the experimental data (solid line; limited to the zone of linearity; dotted lines show the upper and lower $95 \% \mathrm{Cl}$ slopes) and used to calculate (by intrapolation or extrapolation) the time (in $\mathrm{h}$ ) \pm standard deviation needed to reduce the meropenem concentration to $90 \%$ of its original value (see data presented in Table 1 of the main document). $\mathrm{Cl}$, confidence interval. 